\title{
Pseudotumor Cerebri Caused by SARS-CoV-2 Infection in a Boy
}

\author{
Victor Soto Insuga ${ }^{1}$ Verónica Cantarín-Extremera ${ }^{1}$ Inés Solís-Muñoz ${ }^{2}$ Silvia Buendía-Martínez ${ }^{3}$ \\ María Atencia-Ballesteros ${ }^{4}$ Beatriz Bernardino ${ }^{1}$ María Luz Ruiz Falcó ${ }^{1}$
}

1 Department of Neuropediatrics, Niño Jesús Hospital, Madrid, Spain

2 Department of Radiology, Niño Jesus Hospital, Madrid, Spain

${ }^{3}$ Clinical Analysis Laboratory, Niño Jesus Hospital, Madrid, Spain

${ }^{4}$ Department of Ophthalmology, Niño Jesus Hospital, Madrid, Spain
Address for correspondence Victor Soto Insuga, PhD, Department of Neuropediatrics, Niño Jesús Hospital, Madrid, Spain (e-mail: victorsotoinsuga@gmail.com).

J Pediatr Neurol 2021;19:207-209.

Abstract
Keywords
- pseudotumor cerebri
- idiopathic intracranial
hypertension
- SARS-CoV-2
- Mycoplasma
pneumoniae

\section{Introduction}

The neuroinvasive propensity has been reported to be a common feature of infection by coronaviruses such as severe acute respiratory syndrome coronavirus 2 (SARS-CoV-2) (COVID-19). In fact, neurological symptoms are recognized as a frequent manifestation of COVID-19, caused by direct involvement of the nervous system or activation of an exaggerated immune-mediated response. ${ }^{1}$ A study of 214 adult patients with COVID-19 in Wuhan found that $36.4 \%$ had neurological symptoms such as acute cerebrovascular disease, headache, dizziness, impaired consciousness, ataxia, or neuropathy. ${ }^{2}$

So far, there are no reported cases of children with neurological disorders secondary to COVID-19, which could be due to underdiagnosis of the infection because children tend to have fewer symptoms or be asymptomatic.

\section{Case}

A 7-year-old boy consulted for convergent strabismus, blurred vision, and binocular diplopia of 36 hours of evolution without

received

June 11,2020

accepted after revision

July 8,2020

published online

September 2, 2020 headache, vomiting, or pain with eye movements. The neurological examination revealed the presence of bilateral papilloedema and sixth cranial nerve palsy of left eye. The patient was not obese and the rest of the pediatric and neurological examination was normal. The ophthalmological evaluation revealed increased retinal nerve fiber layer thickness showed in optical coherence tomography (154/151 $\mu \mathrm{m}$ right/left eyes) and normal visual acuity (-Fig. 1). He had no personal or family history of interest and his neurodevelopment was normal. Up to 3 days before, the patient had suffered a 2week history of vomiting, cough and fever (maximum temperature $39.2^{\circ} \mathrm{C}$ ), hypogeusia, and hyposmia. Parents had also developed fever and hyposmia.

Magnetic resonance venography imaging was normal. Cerebrospinal fluid (CSF) pressure was $32 \mathrm{~cm} \mathrm{H}_{2} \mathrm{O}$ detected by lumbar puncture after patient sedation. CSF cell count, glucose, protein values, and the study of viruses and bacteria in CSF were normal. Visual-evoked potentials were also normal.

Blood test showed leukocytosis $(16.470 / \mu \mathrm{L})$ without lymphopenia, thrombocytosis (platelets: $1,057,000 / \mu \mathrm{L}$ ), hypertransaminasemia (GOT $84 \mathrm{U} / \mathrm{L}$, GPT $90 \mathrm{U} / \mathrm{L}$ ), and low values of $25-\mathrm{OH}$ vitamin $\mathrm{D}(16.9 \mathrm{ng} / \mathrm{mL})$. Acute phase reactants were

(c) 2020. Thieme. All rights reserved. Georg Thieme Verlag KG, Rüdigerstraße 14,

DOI https://doi.org/ 10.1055/s-0040-1715857. 70469 Stuttgart, Germany 

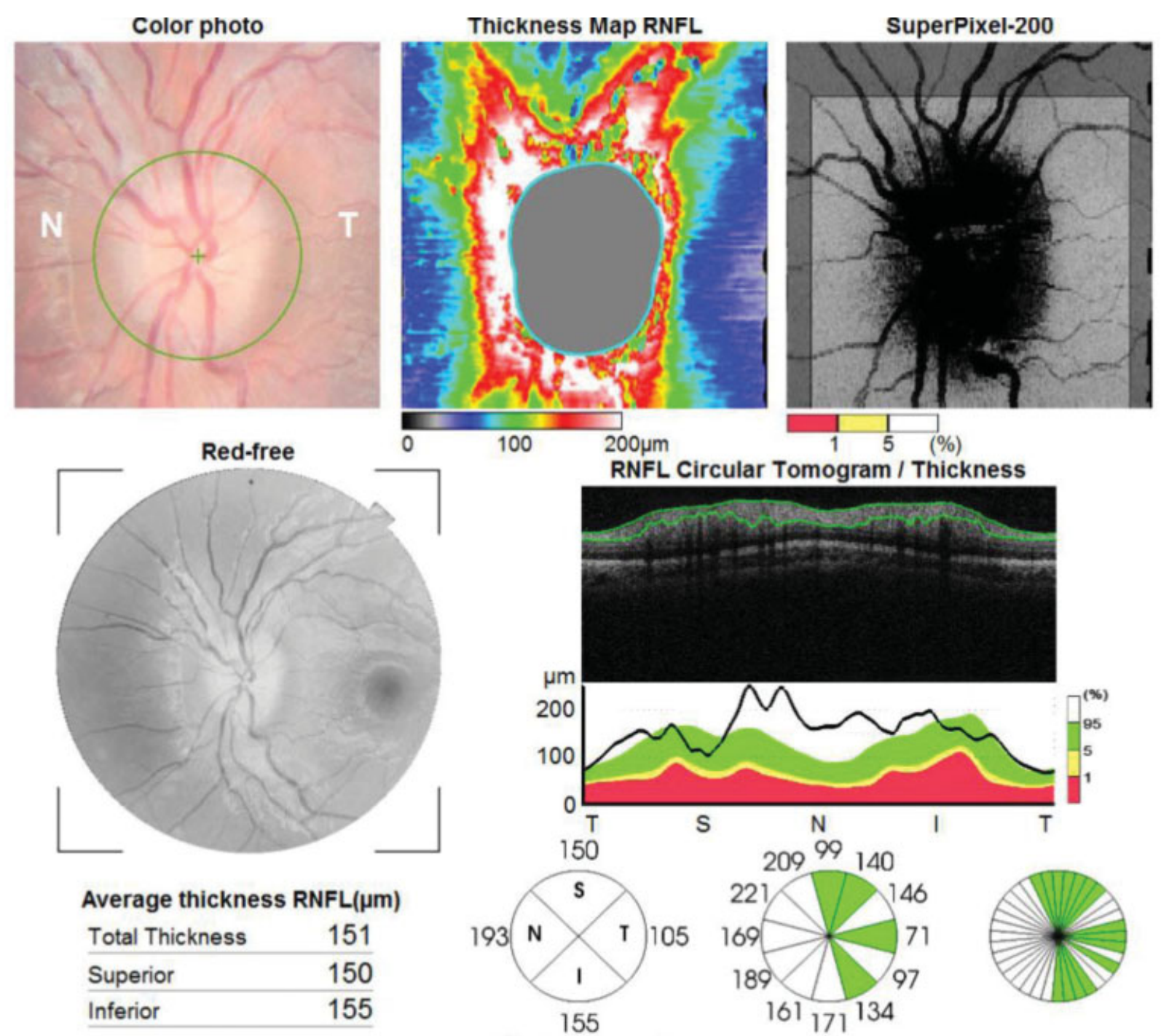

Average thickness $\mathrm{RNFL}(\boldsymbol{\mu} \mathrm{m})$
\begin{tabular}{ll} 
Total Thickness & 151 \\
\hline Superior & 150 \\
\hline Inferior & 155 \\
\hline
\end{tabular}

Fig. 1 Increased retinal thickness showed in optical coherence tomography. RNFL, retinal nerve fiber layer.

high (C-reactive protein $7.71 \mathrm{mg} / \mathrm{dL}$ and ferritin $437 \mathrm{ng} / \mathrm{mL}$ ). A slight increase in fibrinogen $(562 \mathrm{mg} / \mathrm{dL})$ and D-dimer levels $(0.82 \mathrm{mg} / \mathrm{L})$ was observed in coagulation analysis.

Polymerase chain reaction (PCR) SARS-CoV-2 from nasopharyngeal simple was negative. Serology blood tests for herpes simplex virus (types 1 and 2), cytomegalovirus, Epstein-Barr virus, Brucella, Borrelia burgdorferi, and Toxoplasma were negative. Both immunoglobulin $\mathrm{G}(\operatorname{IgG})$ and $\operatorname{IgM}$ of Mycoplasma pneumoniae were positive. Rapid immunochromatographic tests for detection of Ig of SARS-CoV-2 were positive for $\operatorname{IgG}$ and negative for IgM.

Chest radiography and echocardiography were normal. Due to the possible coinfection of COVID-19 and M. pneumoniae, oral azithromycin was initiated for 5 days and low molecular weight heparin due to thrombotic risk. When intracranial hypertension was detected, treatment with intravenous methylprednisolone $(20 \mathrm{mg} / \mathrm{kg} /$ day $)$ was administered for 5 days and oral acetazolamide $(20 \mathrm{mg} / \mathrm{kg} /$ day $)$ was subsequently started. The evolution was excellent. Strabismus and diplopia was resolved 2 days after starting treatment and no recurrences or other complications have been reported.

\section{Discussion}

Pseudotumor cerebri (PC) or idiopathic intracranial hypertension is defined as elevated intracranial pressure with normal cerebrospinal composition, neuroimaging studies, and neurological examination (with the exception of sixth cranial nerve palsy). ${ }^{3}$

The association between PC and infections including hepatitis $\mathrm{E}$, hepatitis A virus, measles, and M. pneumoniae has been described, especially in children. ${ }^{4}$ This relationship seems to be due to inflammatory process, either primary during acute central nervous system infection or secondary to an immune-mediated process, that cause a dysfunction or the absorptive mechanism of the arachnoids' granulations, ending in decreased central nervous system absorption. ${ }^{5}$ These autoimmune mechanisms cause symptoms that appear after active infection, which would justify the negative of our PCR results.

Coinfections of COVID-19 and M. pneumoniae have been described in adult patients. ${ }^{6}$ In this case, the presence of prolonged fever together with hyposmia and hypogeusia 
and the increased C-reactive protein, ferritin, and D-dimer values suggest that this patient had suffered from a SARSCoV-2 infection that may have been the trigger for PC. This is the first case of PC related to COVID-19.

Conflict of Interest

None declared.

\section{References}

1 Shi Y, Wang Y, Shao C, et al. COVID-19 infection: the perspectives on immune responses. Cell Death Differ 2020;27(05): $1451-1454$
2 Mao L, Jin H, Wang M, et al. Neurologic manifestations of hospitalized patients with coronavirus disease 2019 in Wuhan, China. JAMA Neurol 2020:e201127

3 Burkett JG, Ailani J. An up to date review of pseudotumor cerebri syndrome. Curr Neurol Neurosci Rep 2018;18(06):33

4 Mosquera Gorostidi A, Iridoy Zulet M, Azcona Ganuza G, Gembero Esarte E, Yoldi Petri ME, Aguilera Albesa S. Pseudotumour cerebri in children: aetiology, clinical features, and progression. Neurologia 2019;34(02):89-97

5 Ravid S, Shachor-Meyouhas Y, Shahar E, Kra-Oz Z, Kassis I. Viralinduced intracranial hypertension mimicking pseudotumor cerebri. Pediatr Neurol 2013;49(03):191-194

6 Fan BE, Lim KGE, Chong VCL, Chan SSW, Ong KH, Kuperan P. COVID-19 and mycoplasma pneumoniae coinfection. Am J Hematol 2020;95(06):723-724 